\title{
Análise dos roteiros de atividades experimentais nos livros didáticos de Química: um estudo das representações e dos níveis do pensamento químico
}

Analysis of experimental activity scripts in chemistry textbooks: a study of representations and levels of chemical thinking

\author{
Bruna de Paula Rezende ${ }^{1}$ \\ Ana Carolina Araújo da Silva ${ }^{2}$
}

\section{Resumo}

Nos últimos anos, o estudo das representações e seus usos no ensino de química tem sido uma preocupação para a área. Com isso, apresentamos neste artigo partes de um recorte de pesquisa voltado às representações presentes nos roteiros das atividades experimentais investigativas dos livros didáticos de química para o Ensino Médio, aprovados pelo PNLD de 2018. Desse modo, esta pesquisa buscou avaliar e compreender as representações contidas em cinco roteiros e a relação da representação ou do roteiro com os níveis do pensamento químico proposto por Johnstone (2000, 2004). Para atingir tal objetivo, utilizamos pressupostos teóricos metodológicos da análise de conteúdo; identificamos que somente um roteiro é constituído por dois tipos diferentes de representações, enquanto os demais apresentam um único tipo de representação. Ademais, observamos que algumas atividades se limitam a utilizar as representações apenas para compreensão do roteiro experimental e não para auxiliar o entendimento dos conceitos que este aborda. Reforçamos, portanto, que os roteiros experimentais precisam de mais representações e que estas não sejam somente imagens de procedimentos experimentais ou materiais utilizados na prática. Como também, torna-se importante uma melhor abordagem dos três níveis de pensamento químico, em especial, o nível submicroscópico.

Palavras chave: Livros Didáticos; Atividades Experimentais Investigativas; Representações.

\section{Abstract}

In recent years, the study of representations and their uses in teaching chemistry has been a concern for the area. Thus, in this article, we present parts of a research excerpt aimed at representations present in the scripts of investigative experimental activities of high school chemistry textbooks, approved by the PNLD of 2018. Thus, this research sought to evaluate and understand the representations contained in five scripts and the relation of the representation or the script with the levels of chemical thinking proposed by Johnstone (2000, 2004). To achieve this goal, we use theoretical and methodological assumptions from

\footnotetext{
${ }^{1}$ Universidade Federal de Juiz de Fora | rezendebruna@outlook.com

${ }^{2}$ Universidade Federal de Juiz de Fora | anacarolina.silva@ufjf.edu.br
} 
content analysis; we identified that only one script is constituted by two different types of representations, while the others present a single type of representation. Furthermore, we observed that some activities are limited to using representations only to understand the experimental script and not to help understand the concepts it addresses. We emphasize, therefore, that experimental scripts need more representations and that these are not just images of experimental procedures or materials used in practice. As well, it becomes important to better approach the three levels of chemical thinking, in particular, the submicroscopic level.

Keywords: Didatic books; Investigative Experimental Activities; Representations.

\section{Introdução}

Este artigo faz parte de uma pesquisa maior acerca das atividades experimentais investigativas presentes nos livros didáticos (LDS) de química (SILVA; REZENDE, 2020; REZENDE; SILVA, 2021; SILVA; SOUZA; MORAES, 2019). Nessa pesquisa, percebemos que algumas atividades contribuem mais significativamente para a construção de conceitos científicos, pelos estudantes, do que outras. Dessa forma, a literatura tem mostrado que a construção dos significados da química envolve a articulação de três aspectos constituintes do conhecimento químico, que são: fenomenológico, teórico e representacional (simbólico) (Johnstone, 2000, 2004). Essa abordagem foi apresentada pela proposta curricular de química para o Ensino Médio em Minas Gerais (MINAS GERAIS, 1998) e tem sido utilizada por pesquisadores e professores de química nos últimos anos.

Nesse contexto, as atividades experimentais no ensino de química proporcionam a articulação dos níveis do pensamento químico e auxiliam no processo de construção de significados, uma vez que favorecem na compreensão dos fenômenos e na internalização dos conceitos. Desse modo, nos últimos anos inúmeras publicações científicas, nacionais e internacionais, têm respaldado a relevância das atividades experimentais no processo de ensino e de aprendizagem para a área das Ciências da Natureza (GIORDAN, 1999; ANDRADE; VIANA, 2017; GUIMARÃES, 2009; SUART, 2014; ROCHA; MALHEIRO, 2018). Entretanto, sabemos que muitos dos resultados das pesquisas não chegam nas aulas de química. Tal fato, em geral, é justificado pela falta de materiais e de infraestrutura, bem como o pouco tempo que os professores dispõem para organizar as atividades (SUART, 2014). Em razão dessas questões, os LDs têm, cada vez mais, disponibilizado atividades experimentais que sejam acessíveis às escolas brasileiras, e que levem em conta a participação dos estudantes no processo de aprendizado.

Diante disso, as atividades experimentais tornam-se importantes para o ensino, uma vez que elas podem possibilitar que os estudantes estabeleçam elos entre as teorias científicas estudadas em sala de aula e as observações realizadas por esse tipo de atividade.

Para Suart e Marcondes:

[...] se uma aula experimental for organizada de forma a colocar o aluno diante de uma situação problema, e estiver direcionada para a sua resolução, poderá contribuir para o aluno raciocinar logicamente sobre a situação e apresentar argumentos na tentativa de analisar os dados e apresentar uma conclusão plausível. Se o estudante tiver a oportunidade de acompanhar e interpretar as etapas da investigação, ele possivelmente será capaz de elaborar hipóteses, testá-las e discuti-las, aprendendo sobre 
os fenômenos estudados e os conceitos que os explicam, alcançando os objetivos de uma aula experimental, a qual privilegia o desenvolvimento de habilidades cognitivas e o raciocínio lógico (SUART; MARCONDES, 2009, p. 51).

Nesse sentido, há várias estratégias e abordagens para a organização de aulas experimentais presentes nos LDs. Entre as atividades experimentais, presentes nos livros de química, destacam-se as de cunho investigativo. Conforme Sasseron (2015), o ensino investigativo é uma abordagem didática cujo foco principal é fazer com que os estudantes resolvam um problema sobre determinado fenômeno natural, exercitando práticas de análise, avaliação e comparação, ao mesmo tempo em que interagem com seus colegas, com os materiais didáticos e com seus conhecimentos já existentes. Sá, Lima e Aguiar Jr (2011) argumentam que as atividades investigativas são consideradas estratégias, entre outras, que o professor pode utilizar para diversificar a sua prática no cotidiano escolar.

A partir dessas diferentes possibilidades de trabalhar a experimentação, podemos perceber que muitas dessas atividades exploram o nível visível dos estudantes. De acordo com Johnstone (2000, 2004), o conhecimento químico pode ser organizado em três níveis macroscópico, submicroscópico e representacional, que são: nível descritivo e funcional (macroscópico), no qual pode-se observar e descrever as transformações da matéria, por meio dos sentidos e das propriedades das substâncias; nível simbólico (representacional), cuja abordagem se dá com o uso de fórmulas, equações e esquemas; e nível explicativo (submicroscópico), que leva em consideração a interação entre átomos, íons, moléculas e estruturas na construção de modelos explicativos. Essa articulação dependerá da proposição da atividade ou do roteiro e das questões presentes. Para o autor, a transição pelos três níveis do pensamento químico poderia ocorrer nos estágios iniciais da aprendizagem, para isso, ele sugere uma reestruturação das atividades, apontando que uma das formas seria trabalhar um vértice do triângulo de cada vez, iniciando pelo que é familiar ou interessante para o aluno, utilizando seus conhecimentos prévios e a partir destes introduzir e construir novos conhecimentos. Portanto, as atividades de cunho experimental podem possibilitar a articulação entre os três diferentes níveis do pensamento químico organizados por Johnstone (2000, 2004).

É importante ressaltar que apesar de não existir predominância de um nível sobre o outro, experiências em sala de aula mostram que o nível submicroscópico é considerado como o mais difícil de ser compreendido entre os três, pois exige dos estudantes a construção de modelos mentais que demandam um desenvolvimento cognitivo mais avançado. Desse modo, as aulas de química trabalham com muitos objetos do nível abstrato que não são diretamente acessíveis à percepção, sendo necessária uma representação, seja ela por símbolos, códigos, tabelas, gráficos, algoritmos ou desenhos. Essas representações permitem a comunicação entre os sujeitos e as atividades cognitivas do pensamento, possibilitando registros de diferentes formas de representar um mesmo objeto (DAMM, 2008).

Desse modo, as representações podem ser entendidas como modelos conceituais que representam de forma simplificada objetos, fenômenos ou situações. Elas são utilizadas para facilitar a compreensão de conceitos durante o processo de ensino e de aprendizagem. Assim sendo, existem diferentes formas de representação, entre elas: imagens; gráficos; fotografias; analogias; fórmulas matemáticas; símbolos, entre outros (ORNEK, 2008). Para Schönborn e Anderson (2006), é possível definir as representações como modelos criados 
para auxiliar o entendimento de conceitos. Enquanto, as múltiplas representações referemse à prática de representar um mesmo conceito ou processo químico por diferentes modos. Esses modos podem ser verbais, gráficos, numéricos, escritos e simbólicos (PRAIN; WALDRIP, 2006).

Diante do exposto, é fato que o estudo das representações no ensino de química tem sido de preocupação para a área (SOUZA; PORTO, 2011; CANCIAN; RAMOS, 2019; ROZENTALSKI; PORTO, 2015). Desse modo, esta pesquisa visa caracterizar as representações contidas nas atividades experimentais presentes nos LDs de química para o Ensino Médio aprovados pelo Programa Nacional do Livro e do Material Didático (PNLD) de 2018. Cabe destacar que este estudo de análise dos LDs é intencional, pois advém do interesse das pesquisadoras que já realizam pesquisas com os LDs do Ensino Médio (SILVA; REZENDE, 2020; REZENDE; SILVA, 2021). Assim, a questão investigada envolve compreender: quais são as atividades experimentais investigativas e representações presentes nos LDs de química do Ensino Médio, pertencentes ao PNLD? Quanto ao objetivo, o artigo pretende apresentar uma análise que visa identificar os tipos de representações presentes nas atividades experimentais investigativas dos LDs de química do Ensino Médio e caracterizar suas possibilidades e limitações. Além disso, a ideia desta investigação é impulsionar a compreensão sobre materiais didáticos de química, especificamente na área de Ciências da Natureza.

\section{Procedimento Metodológico}

Este artigo apresenta um estudo cuja abordagem é qualitativa. A pesquisa qualitativa baseia-se na obtenção de dados descritivos que são gerados pelo contato do pesquisador com sua fonte de dados, ou seja, o pesquisador é o principal instrumento de coleta dos dados. Além disso, a pesquisa qualitativa demonstra enfoque indutivo, é descritiva e preocupa-se com o entendimento do fenômeno como todo, priorizando os processos, em vez dos resultados ou produtos (GODOY, 1995; BOGDAN; BIKLEN, 1994).

As fontes de conteúdo, neste estudo, são os LDs de química. Os dados obtidos a partir da análise dos livros "são designados por qualitativos, o que significa ricos em pormenores descritivos relativamente a pessoas, locais e conversas, e de complexo tratamento estatístico" (BOGDAN; BIKLEN, 1994, p. 16). Para atingir o objetivo da pesquisa, adotamos os pressupostos teóricos da análise de conteúdo (BARDIN, 2016). A análise de conteúdo é definida como um conjunto de técnicas que empregam métodos sistemáticos e objetivos de descrição de indicadores, que podem ser quantitativos ou não. Essas técnicas permitem, ao final da análise, a interpretação dos dados coletados (BARDIN, 2016).

Nesse contexto, em uma pesquisa anterior, analisamos os roteiros das atividades experimentais presentes nos LDs de química do Ensino Médio aprovados pelo PNLD de 2018 e classificamos as atividades em simples ou investigativas. As atividades experimentais de cunho investigativo podem proporcionar aos estudantes elaborar e testar hipóteses, investigar um problema, coletar e analisar dados e elaborar conclusões com os resultados obtidos, além de favorecer uma maior interação entre os alunos e entre o docente e os alunos (MARCONDES; SOUZA; SUART, 2009). Dessa forma, as atividades experimentais que foram caracterizadas como investigativa favoreciam aos professores trabalharem a partir de um problema e/ou permitiam o levantamento de hipóteses pelos discentes. 
Conforme Franco (2005), definido os objetivos da pesquisa, determinado o referencial teórico e conhecido o material a ser analisado, o pesquisador passa para a definição das unidades de análise presentes na etapa de codificação. Essa etapa, para Bardin (2016), envolve o trabalho com os dados brutos da pesquisa, que são transformados por meio de recortes, a fim de auxiliar na elucidação das características do material analisado.

As unidades de análise, dividem-se em: unidades de registro e unidades de contexto. As unidades de registro são a menor parte do conteúdo, ou seja, as unidades de base e podem ser uma palavra; um tema; personagem; acontecimento; um objeto, entre outras. Já a unidade de contexto é a parte mais ampla do conteúdo a ser analisado, sendo de fundamental importância para o entendimento das unidades de registro (BARDIN, 2016; FRANCO, 2005).

Segundo Bardin (2016), existem três polos cronológicos para a análise de conteúdo. O primeiro polo, pré-análise, baseia-se na definição do corpus de análise, na leitura flutuante das atividades experimentais presentes nos LDs e na elaboração de indicadores que permitem a interpretação das atividades selecionadas. Dessa forma, definimos como corpus de análise as atividades experimentais contidas nos LDs aprovados no PNLD de 2018. No Quadro 1, apresentamos a identificação do livro didático, o título, a editora, o nome dos autores ou coordenadores/organizadores e o seu código.

Quadro 1: Identificação dos Livros Didáticos

\begin{tabular}{|c|c|c|}
\hline Livro Didático & $\begin{array}{r}\text { Título; editora; nome dos autores ou } \\
\text { coordenadores/organizadores }\end{array}$ & Código \\
\hline LD1 & Vivá Química; editora Positivo; Novais e \\
Tissoni & 0153 P18123 \\
\hline LD2 & $\begin{array}{r}\text { Química; editora Scipione; Andréa Horta } \\
\text { Machado e Eduardo Fleury Mortimer }\end{array}$ & 0041 P18123 \\
\hline LD3 & $\begin{array}{r}\text { Química Ser Protagonista; editora SM; edições } \\
\text { SM }\end{array}$ & 0074 P18123 \\
\hline LD4 & Química; editora Moderna; Ciscato, Pereira, & 0185 P18123 \\
\hline LD5 & Química; editora Ática, Martha Reis & 0020P18123 \\
\hline LD6 & Química Cidadã; editora AJS; Wildson Santos & 0206P18123 \\
\hline
\end{tabular}

Fonte: Autoria própria (2020)

O segundo polo consiste na exploração do material e na categorização das atividades. Assim, na exploração do material, realizamos uma sequência de operações que visam decompor os dados em função das especificações formuladas previamente. A categorização representa a classificação das atividades em critérios definidos pelo pesquisador (BARDIN, 2016).

Logo, a exploração dos LDs, envolveu inicialmente a contagem das atividades experimentais, simples e investigativas, no qual o tema soluções obteve o maior número de atividades. Posteriormente, foram identificados os roteiros das atividades experimentais investigativas pertencentes à temática soluções. Em seguida, identificamos os tipos de representações contidas nelas. Sendo que as representações mais encontradas nessas 
atividades foram: tabelas, gráficos, quadros, diagramas, imagens, expressões matemáticas, estruturas de compostos químicos e equações químicas. Visto que o objetivo de nossa pesquisa é explorar as atividades experimentais investigativas, sendo assim optamos por trabalhar neste artigo somente com esse tipo de atividade.

Por fim, o terceiro polo consiste na inferência e na interpretação dos recortes das atividades experimentais, que são as unidades de contexto desta pesquisa. Os recortes são partes das atividades que nos fornecem as características daquela atividade. Essas características, além de serem os indicadores deste estudo, também são as unidades de registro. Nessa fase, procuramos compreender os dados e as informações obtidas a partir da análise dos roteiros das atividades experimentais.

\section{Resultados e discussões}

Para este estudo, analisamos cinco roteiros de Atividades Experimentais Investigativas contidas nos LDs de química aprovados pelo PNLD de 2018. No Quadro 2, destacamos algumas particularidades de cada roteiro escolhido, como: identificação, característica investigativa do roteiro e os tipos de representações que apresentam.

Quadro 2: Identificação e características dos Roteiros Experimentais

\begin{tabular}{|c|c|c|c|c|c|c|}
\hline \multirow[t]{2}{*}{ Roteiro } & \multirow{2}{*}{$\begin{array}{l}\text { LD, } \\
\text { volume, } \\
\text { página }\end{array}$} & \multirow{2}{*}{$\begin{array}{c}\text { Característica } \\
\text { investigativa }\end{array}$} & \multicolumn{4}{|c|}{ Tipos de representações } \\
\hline & & & Imagens & Quadros & $\begin{array}{l}\text { Equações } \\
\text { químicas }\end{array}$ & Gráficos \\
\hline 1 & $\begin{array}{l}\text { LD1, vol. } \\
\text { 2, p. } 32\end{array}$ & Problema & 1 & - & - & - \\
\hline 2 & $\begin{array}{c}\text { LD2, vol. } \\
\text { 3, p. } 154- \\
156\end{array}$ & Hipótese & - & 2 & - & - \\
\hline 3 & $\begin{array}{l}\text { LD4, vol. } \\
2 \text {, p. } 25- \\
27\end{array}$ & Problema & - & - & 2 & - \\
\hline 4 & $\begin{array}{l}\text { LD6, vol. } \\
\text { 2, p. } 84\end{array}$ & Problema & 3 & - & - & 1 \\
\hline 5 & $\begin{array}{l}\text { LD5, vol. } \\
\text { 2, p. } 112\end{array}$ & Problema & 1 & - & - & - \\
\hline
\end{tabular}

Fonte: Autoria própria (2020).

Conforme Ornek (2008), as representações podem ser entendidas como modelos conceituais que representam de forma simplificada objetos, fenômenos ou situações. Sendo assim, elas são utilizadas para facilitar a compreensão de conceitos durante o processo de ensino e de aprendizagem. Existem diferentes formas de representação, entre elas: imagens; gráficos; fotografias; analogias; fórmulas matemáticas; símbolos etc. (ORNEK, 2008). Para Schönborn e Anderson (2006), é possível definir as representações como modelos criados para auxiliar o entendimento de conceitos. Nesse sentido, identificamos nos roteiros estudados 4 tipos de representações, a saber: imagens; no qual, foram classificadas nessa 
categoria as imagens relacionadas ao procedimento experimental ou aos materiais utilizados na prática; quadros; equações químicas e gráficos.

Dessa forma, ao analisar o Quadro 2, identificamos que o roteiro 1 e o roteiro 5 apresentam somente uma imagem relacionada ao procedimento experimental. Enquanto, o roteiro 2 apresenta dois quadros e o roteiro 3 duas equações químicas. Já o roteiro 4 é o único constituído por dois tipos diferentes de representações. Esse roteiro apresenta três imagens relacionadas aos materiais necessários para uso na prática e um gráfico. Em relação às características investigativas de cada roteiro, verificamos que quatro atividades experimentais apresentam como característica um problema e apenas uma apresenta 0 levantamento de hipóteses.

\section{Análise dos tipos de Representaç̃̃es: Compreendendo suas possibilidades e limitações}

O roteiro 1 está presente no volume 2 do LD1 no capítulo "Soluções e dispersões coloidais: aspectos gerais". Esse capítulo aborda os conceitos de estados físicos das soluções, o que é solubilidade e os tipos de dispersões. O objetivo da atividade experimental é verificar a diferença entre a propagação da luz por uma dispersão do tipo solução e por uma dispersão do tipo coloidal.

Os roteiros experimentais presentes no LD1 estão localizados na seção "Química: prática e reflexão". Conforme Novais e Antunes (2016), essa seção é composta por experimentos que possuem orientações e recomendações de segurança necessárias para a realização das práticas, além de questões que estimulam a reflexão por parte dos estudantes.

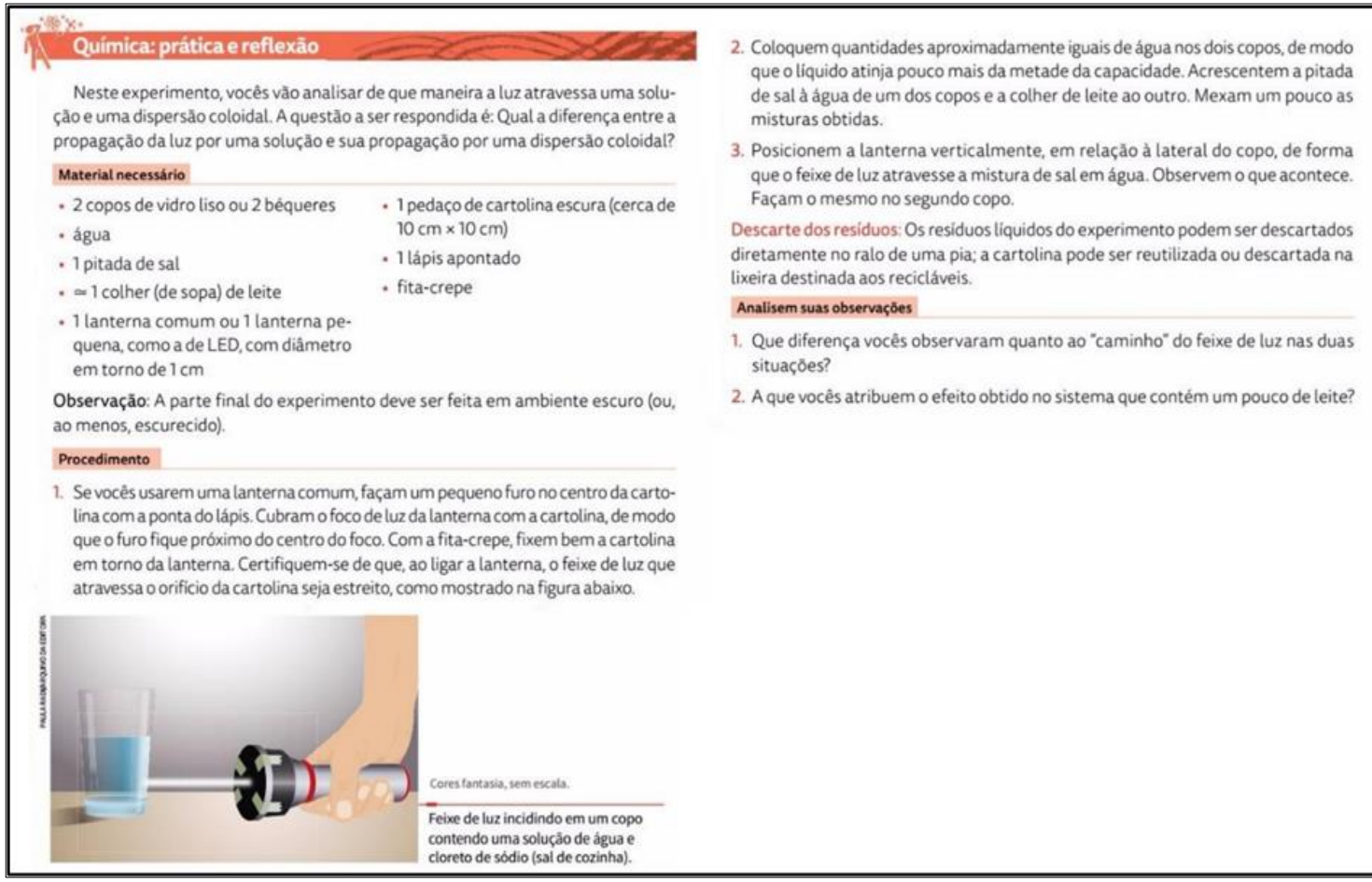

Figura 1: Roteiro 1. Fonte: LD1, volume 2, p. 32 (2016) 
O roteiro 1 apresenta uma imagem que é utilizada para complementar o texto escrito no item 1 do procedimento. Também é possível observar que a imagem gera um maior sentido para o aluno a partir do momento em que ele lê o roteiro da atividade. Dessa forma, a imagem por si só não representa de modo claro qual o procedimento que o estudante deve adotar para fazer com que a lanterna apresente somente um feixe de luz. Além disso, a legenda proposta complementa a imagem.

Dessa maneira, compreendemos que as imagens nas aulas de Ciências possuem um papel importante para a construção e compreensão de conceitos científicos, constituindo-se como prática fundamental de ensino (SILVA et al., 2006). De acordo com Silva et al. (2006, p. 221), "a imagem não é concebida como transmissora de informação, mas parte de um processo mais amplo de produção/reprodução de sentidos". Isto posto, entendemos, assim como Tomio et al. (2013, p. 27) que "os significados para uma imagem surgem na interação do sujeito leitor com a imagem, a partir das particularidades e restrições de um contexto", sendo fundamental que o leitor compreenda bem a imagem e o contexto na qual estão inseridos.

A questão inicial proposta pelos autores como problema: "Qual a diferença entre a propagação da luz por uma solução e sua propagação por uma dispersão coloidal?", propõe que as soluções não são um tipo de dispersão. Acreditamos que a melhor maneira de abordar essa questão seria: qual a diferença entre a propagação da luz por uma dispersão do tipo solução e sua propagação por uma dispersão do tipo coloidal?

Ressaltamos que a imagem proposta na atividade experimental concretiza o experimento e não os conceitos envolvidos na atividade. Sendo assim, a limitação de alguns roteiros é utilizar as representações para compreensão do procedimento experimental e não do conceito. Porém, esse roteiro auxilia os alunos a compreenderem não apenas a atividade experimental, mas também a diferença entre dispersões do tipo solução e do tipo coloidal (dispersões coloidais).

O roteiro 2 pertence ao volume 3 do LD2 e localiza-se no capítulo "Água nos ambientes urbanos: Química para cuidar do planeta". Esse capítulo envolve uma série de experimentos que visam determinar a qualidade da água. Os autores propõem atividades de determinação do oxigênio dissolvido na água, construção de um turbidímetro para medição da turbidez da água, medição do pH e condutividade, entre outros. O objetivo da atividade experimental proposta no roteiro 2 é determinar a quantidade de oxigênio dissolvido em amostras de água colhidas pelos alunos.

Neste capítulo, os autores trabalham de forma contextualizada, uma vez que a partir do tema água, eles desenvolvem uma série de atividades que envolvem conceitos químicos. Para Guimarães (2009, p. 199), "ao utilizar a experimentação, associando os conteúdos curriculares ao que o educando vivenciou, o educador trabalhará de forma contextualizada".

Desse modo, os roteiros experimentais presentes no LD2 estão localizados na seção "Investigação". Conforme Mortimer e Machado (2016), essa seção apresenta atividades que são acompanhadas de questões que buscam propiciar o diálogo entre os estudantes com os fenômenos em foco. 


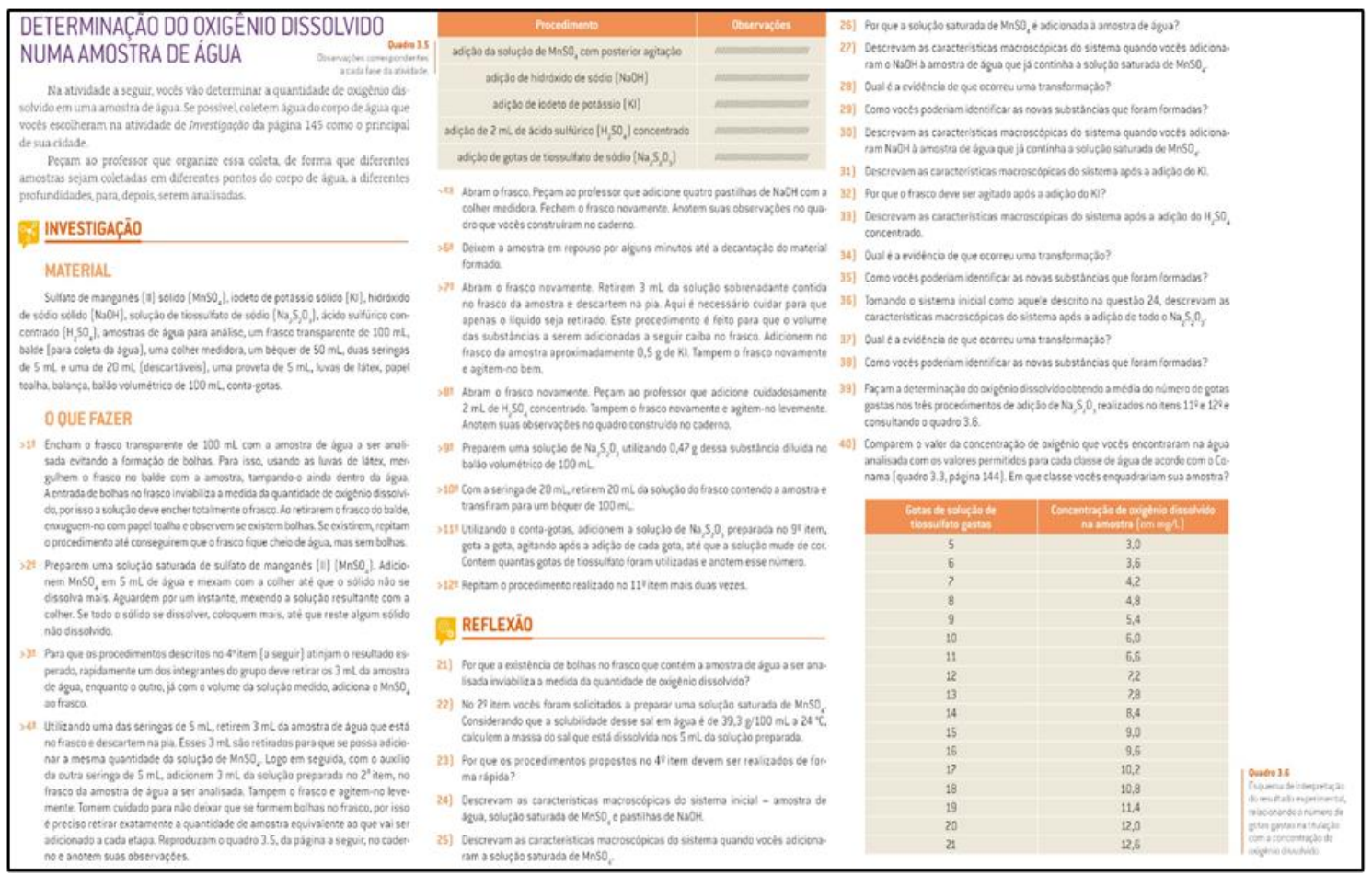

Figura 2: Roteiro 2. Fonte: LD2, volume 3, p. 154-156 (2016)

O roteiro 2 apresenta dois quadros como forma de representação. O quadro 3.5 proposto pelos autores, para os alunos construírem, pode auxiliar os estudantes na organização dos dados observados durante a realização da prática experimental. Na análise da atividade, avaliamos que sem a sugestão desse quadro, os discentes poderiam se perder durante as suas anotações, pois são utilizados cinco diferentes reagentes durante a atividade.

Em relação às questões propostas na seção "Reflexão", na pergunta 22 o roteiro permite que os discentes utilizem artifícios matemáticos para calcular a massa do sal dissolvida na solução que foi preparada. Enquanto, em algumas questões (24, 25, 27, 30, 31 e 33), os autores solicitam que os estudantes descrevam características macroscópicas dos sistemas propostos que foram utilizados e observados durante a prática. Acreditamos que essas questões poderiam ter sido solicitadas a partir das representações microscópicas e simbólicas dos sistemas, pois assim os estudantes utilizariam os três níveis de representação do conhecimento químico: macroscópico, submicroscópico e simbólico (JOHNSTONE, 2000, 2004). Por fim, o quadro 3.6 apresenta um esquema que permite aos estudantes relacionarem as gotas gastas de tiossulfato com a concentração de oxigênio dissolvido na amostra da água. O quadro facilitará a visualização dos dados.

O roteiro 3, localizado no volume 2 do LD4, apresenta o tema "As principais formas de expressar as concentrações dos solutos nas soluções". Tal assunto aborda os conceitos de soluções concentradas e diluídas; o preparo de soluções a partir de sólidos; a concentração de gás oxigênio na água e as formas de expressar concentrações: partes por milhão (ppm), partes por bilhão (ppb), porcentagem, título, gramas por litro $(\mathrm{g} / \mathrm{L})$ e quantidade de matéria. Assim como o roteiro 2, o roteiro 3 apresenta como proposta a determinação da quantidade de oxigênio dissolvido em uma amostra de água.

As atividades experimentais do LD4 estão disponibilizadas na seção "Atividade prática". De acordo com Ciscato et al. (2016), essa seção contém atividades simples e investigativas que apresentam normas de segurança, orientações sobre descarte de resíduos e 
questionamentos que conduzem os alunos na interpretação dos resultados e na obtenção de conclusões.

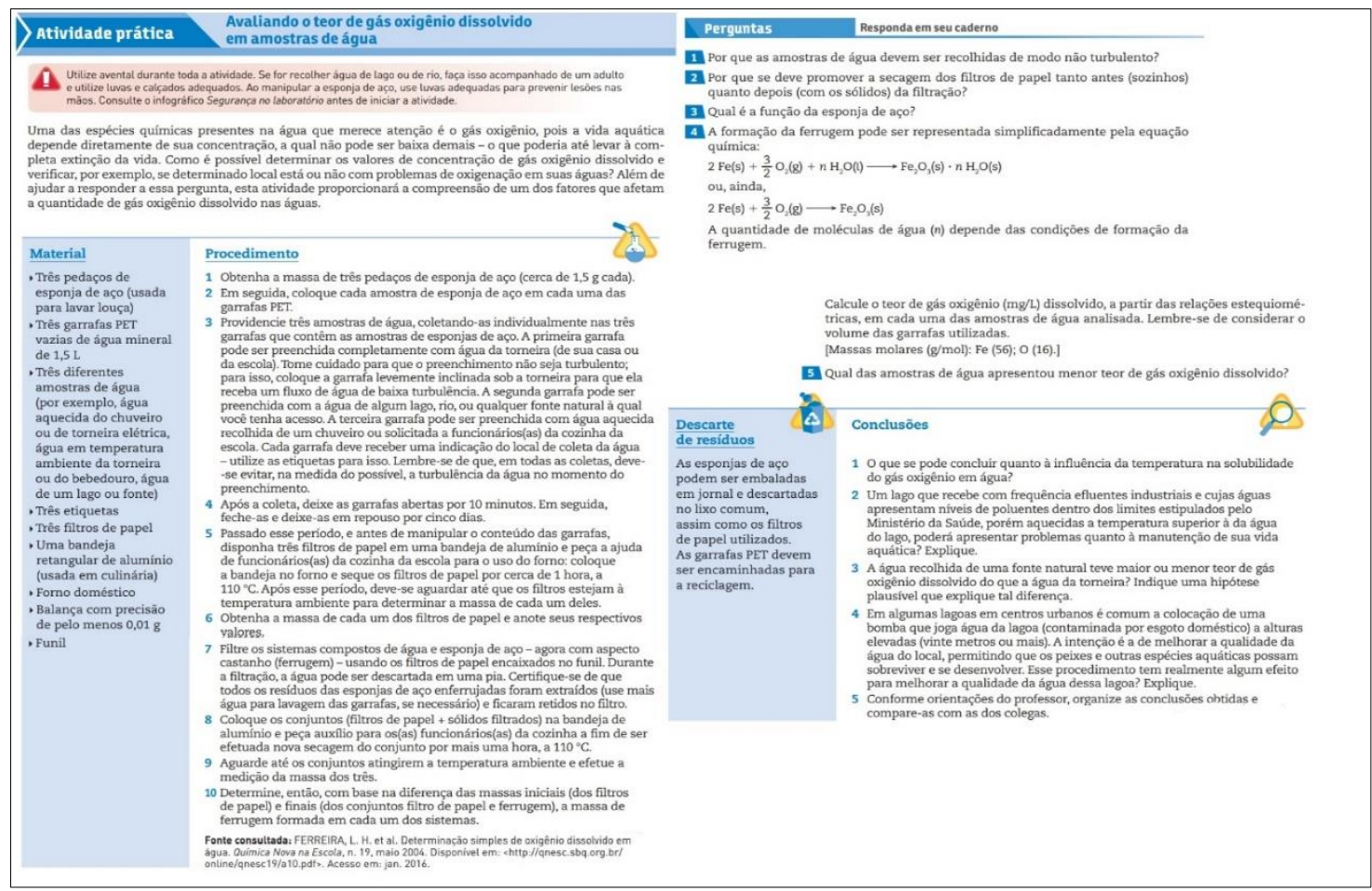

Figura 3: Roteiro 3. Fonte: LD4, volume 2, p. 25-27 (2016)

O roteiro 3 utiliza na questão 4, seção perguntas, duas equações químicas como forma de representação e permite que os alunos utilizem expressões matemáticas para calcular o teor de gás oxigênio dissolvido nas amostras. Sendo assim, a questão 4 apresenta duas outras formas de representar o que foi descrito e realizado na seção experimental, garantindo múltiplas representações da atividade. Acreditamos que o roteiro poderia usar uma imagem ou esquema como forma de auxiliar o entendimento da atividade experimental por parte dos estudantes. Além disso, a forma como os autores solicitam dos estudantes o cálculo do teor de oxigênio dissolvido, pode proporcionar uma compreensão equivocada sobre a formação de ferrugem. Desse modo, os alunos poderiam compreender que o processo de ferrugem acontece como indicado pela questão 4, equação química e cálculo do teor de oxigênio dissolvido, não sendo essas as únicas formas de explicar esse fenômeno (WEISS; LAMBACH, 2019). Nisso, pode-se mostrar aos discentes a Ciência como algo feito e acabado e não como parte de um processo.

Destacamos, também, que ao contrário do que é solicitado nas perguntas do roteiro 2, o roteiro 3 disponibiliza a representação simbólica do fenômeno ocorrido durante a prática. Desse modo, compreendemos que os modos macroscópico e microscópico poderiam ter sido solicitados aos estudantes. De acordo com Pozo e Gomes Crespo (1998) (apud NúÑ̃EZ; RAMALHO; PEREIRA, 2011) há certa dificuldade, por parte dos discentes, na compreensão do significado químico embutido nas equações químicas. Esse fato, em geral, é justificado, pela dificuldade que os alunos apresentam em diferenciar o nível macroscópico do microscópico.

O roteiro 4 pertence ao volume 2 do LD6 e localiza-se no capítulo "Cálculos químicos: estequiometria e soluções". Nesse capítulo, são abordados os conceitos de estequiometria, 
rendimento de reações, balanceamento de equações químicas, soluções, concentração, composição, diluição, propriedades coligativas e produtos químicos domésticos. O objetivo da atividade prática é analisar a volatilidade de três substâncias químicas encontradas em nosso cotidiano: água, álcool e acetona (solvente para limpeza de esmalte).

As atividades experimentais presentes no LD6 podem ser encontradas na seção "Atividade Experimental". Conforme os coordenadores Santos e Mól (2016), a seção é constituída por uma série de experimentos investigativos que propiciam aos estudantes trabalhar com tabelas e gráficos, além da preocupação com o meio ambiente e a segurança.

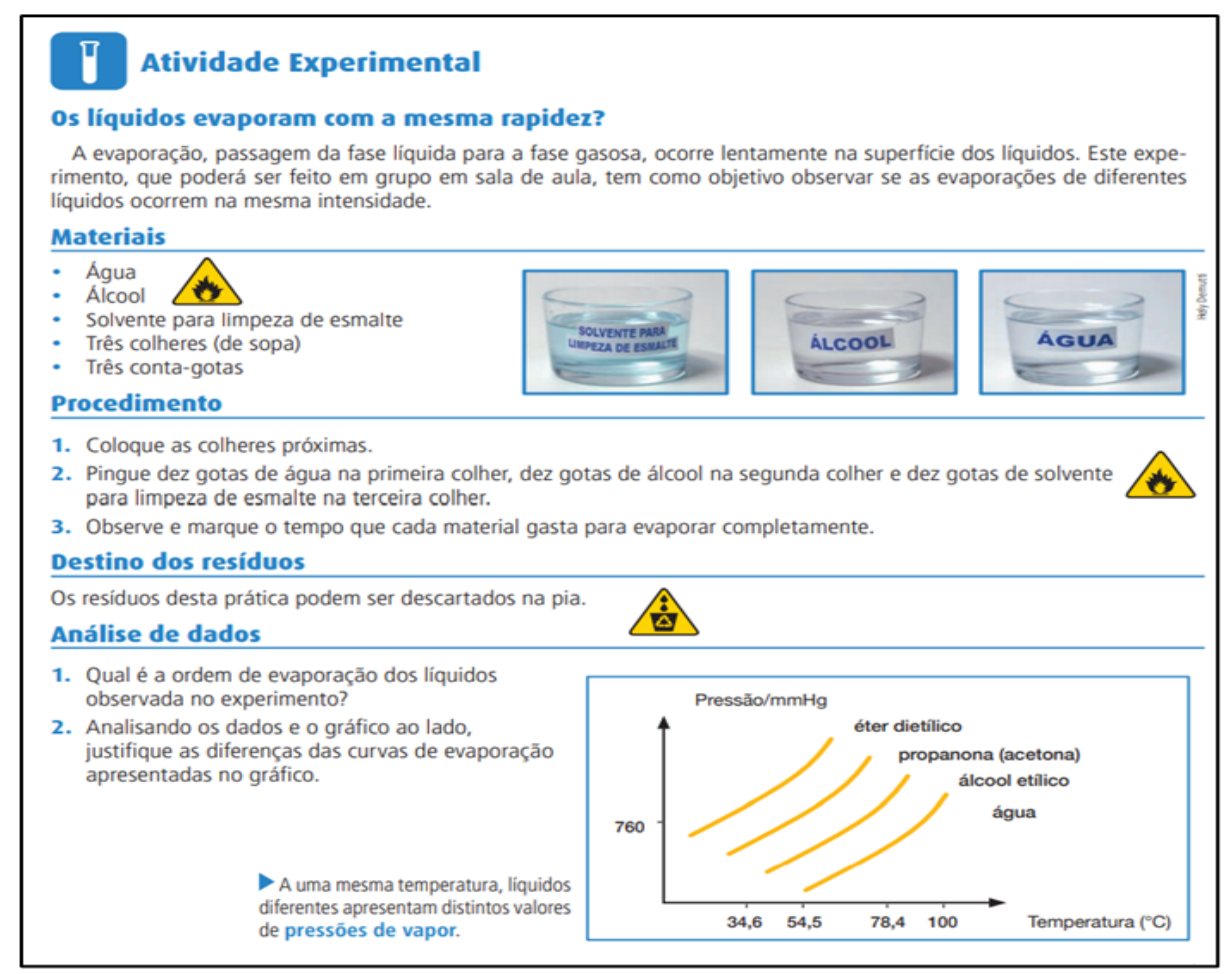

Figura 4: Roteiro 4. Fonte: LD6, volume 2, p. 84 (2016)

O roteiro 4 apresenta como formas de representação uma imagem dos materiais necessários para a prática e um gráfico. O gráfico apresentado pelos autores representa as curvas de evaporação dos compostos éter dietílico, propanona, álcool etílico e água, dos quais três deles foram utilizados na atividade experimental. Nesse sentido, o gráfico expressa uma forma de representação da atividade experimental e contribui significativamente para o entendimento da atividade. Além disso, ele complementa, finaliza e reforça a atividade prática, ou seja, o que foi observado pelos estudantes.

O roteiro 5 pertence ao volume 2 do LD5, sendo encontrado no capítulo "Propriedades coligativas". Nesse capítulo, a autora trabalha com os conceitos de propriedades coligativas, tonoscopia, ebulioscopia, crioscopia e osmoscopia. O roteiro apresenta como questão central, a seguinte problemática: "Como "pescar" um cubo de gelo com um barbante?".

Segundo Reis (2016), os experimentos que compõem o LD5 são investigativos, eles introduzem um assunto, despertam questionamentos e provocam nos discentes vontade de continuar aprendendo, além disso, os experimentos são acessíveis e preocupam com a segurança e o meio ambiente. As atividades experimentais do LD5 estão localizadas na seção "Experimento". 


\section{Experimento}

\section{Como "pescar" um cubo de gelo com um barbante?}

\section{Material necessário}

- 1 copo de vidro transparente

- água fria

- 1 cubo de gelo grande

- 1 pedaço de barbante de cerca de $30 \mathrm{~cm}$

- sal de cozinha, $\mathrm{NaCl}(\mathrm{s})$

\section{Como fazer}

Encha o copo com água deixando 2 dedos de borda. Coloque o cubo de gelo no centro do copo. Pegue uma das extremidades do barbante e deite um pedaço de $3 \mathrm{~cm}$ sobre o cubo de gelo. 0 que acontece se você puxar o barbante? 0 gelo vem junto?

Arrume novamente a extremidade do barbante sobre o cubo de gelo e adicione sal sobre o conjunto gelo + barbante. Aguarde um instante e puxe o gelo do copo com água.
0 que acontece?

\section{Investigue}

1. Qual o efeito causado pelo sal que faz o barbante "grudar" no cubo de gelo?

2. Outra substância no lugar do sal poderia causar o mesmo efeito? Por quê?

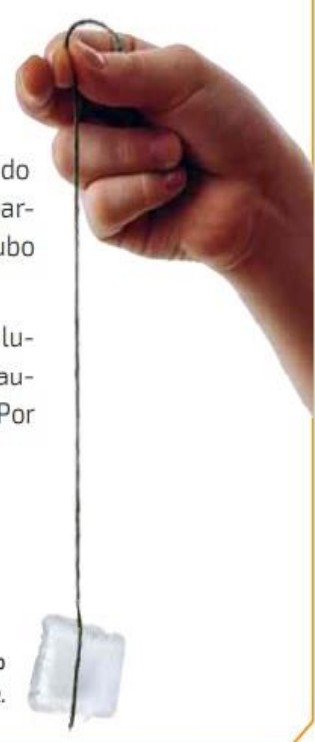

Figura 5: Roteiro 5. Fonte: LD4, volume 2, p. 112 (2016)

O roteiro 5, ao contrário dos demais roteiros, pode causar certa confusão no estudante. A princípio, a primeira impressão que se tem ao olhar a imagem é que o cubo de gelo está amarrado no barbante. Para solucionar essa questão, propomos que o barbante seja estendido um pouco mais na extremidade inferior do cubo de gelo, o que proporciona uma certeza maior de que o gelo está pendurado no barbante. Outro ponto observado é que a legenda poderia ser mais clara, por exemplo, os autores poderiam ter citado que esse sistema representa o conjunto gelo+barbante+sal.

Por fim, observamos nas figuras que o uso das representações nos roteiros experimentais auxilia os estudantes no entendimento de procedimentos, na organização de dados, na visualização de conceitos, na compreensão dos níveis do pensamento químico (macroscópico, submicroscópico e simbólico) e na interpretação de gráficos e diagramas. Sendo, portanto, de grande importância para o ensino e aprendizado, em especial, o de química.

\section{Considerações}

Neste artigo, apresentamos partes de um recorte de pesquisa voltado ao estudo das representações presentes nos roteiros das atividades experimentais investigativas dos LDs de química para o Ensino Médio, aprovados pelo PNLD de 2018. Este estudo buscou avaliar e compreender as representações contidas em cada roteiro e a relação da representação ou do roteiro com os níveis do pensamento químico proposto por Johnstone $(2000,2004)$

Verificamos que quatro atividades experimentais apresentam como características investigativa um problema e apenas uma exibe o levantamento de hipóteses. Em relação aos tipos de representação, encontramos nesses roteiros quatro tipos diferentes, são eles: imagens - estas foram classificadas nessa categoria como imagens relacionadas ao procedimento experimental ou aos materiais utilizados na prática - quadros; equações 
químicas e gráficos. Consequentemente, identificamos que o roteiro 4 é o único constituído por dois tipos diferentes de representações, enquanto os demais apresentam um único tipo de representação. Ressaltamos que cada representação tem um objetivo específico na atividade experimental, além disso ela busca favorecer o entendimento do desenvolvimento para os estudantes.

Ademais, observamos que algumas atividades se limitam a utilizar as representações apenas para compreensão do roteiro experimental e não para auxiliar o entendimento dos conceitos que são abordados. Também foi possível verificar que algumas imagens, em especial as relacionadas ao procedimento experimental, geram um sentido maior para o aluno a partir do momento em que ele lê o roteiro da atividade.

Averiguamos que algumas formas de representação, por exemplo, os quadros do roteiro 2 podem auxiliar os alunos na organização dos dados durante a realização da prática experimental. Nesse contexto, cada representação possui uma finalidade que quando combinada com o modo escrito dos roteiros auxiliam de forma significativa os estudantes. No entanto, nem sempre as representações são de conceitos envolvidos nas práticas, e sim de formas de se realizar o experimento, como os roteiros 1 e 5 .

Reforçamos que os roteiros experimentais precisam de mais representações e que estas não sejam somente imagens de procedimentos experimentais ou materiais utilizados na prática. Bem como, é necessária uma melhor abordagem dos três níveis do pensamento químico, em especial, o nível submicroscópico.

A principal limitação desse estudo, como citado anteriormente, é que os autores necessitam utilizar nos roteiros experimentais mais formas de representações relacionadas aos conceitos abordados e representações que auxiliem os estudantes na visualização dos três níveis do pensamento químico. Nesse sentido, questionamos: Por que não há a abordagem, por parte dos autores, dos três níveis do pensamento químico nas atividades, visto que algumas questões abrem espaço para esse tipo de abordagem? As representações como apresentadas nos LDs aprovados no PNLD de 2018 auxiliam ou limitam os estudantes? Por que não há ou há poucas representações que abordam os conceitos científicos nos roteiros experimentais? Esses questionamentos abrem espaço para futuras pesquisas relacionadas as representações presentes nos LDs de química.

Portanto, compreendemos que este trabalho pode auxiliar futuros e atuais professores de química a identificarem os tipos de representações presentes nos LDs; a forma com que os livros exploram essas representações; o modo com que planejam e executam práticas experimentais em sala de aula.

\section{Referências}

ANDRADE, R. S.; VIANA, K. S. L. Atividades experimentais no ensino da química: distanciamentos e aproximações da avaliação de quarta geração. Ciênc. Educ., Bauru, v. 23, n.2, p. 507-522, 2017.

BARDIN, L. Análise de conteúdo. Tradução Luís Antero Reto, Augusto Pinheiro. São Paulo: Edições 70, 2016.

BOGDAN, R. C.; BIKLEN, S. Investigação qualitativa em educação. Tradução Maria João Alvarez, Sara Bahia dos Santos e Telmo Mourinho Baptista. Porto: Porto Editora,1994. 
CANCIAN, C. de C. B.; RAMOS, R. de C. A. N. Estudo semiótico de imagens sobre Ligações Químicas em livros didáticos para o $1^{\circ}$ ano do Ensino Médio. Educação Química en Punto de Vista, v. 3, n. 1, p. 1-17, 2019

CISCATO, C. A. M.; PEREIRA, L. F.; CHEMELLO, E.; PROTI, P. B. Química: Ensino Médio. $1^{a}$ Ed. São Paulo: Moderna, 2016, v. 2.

DAMM, R. F. Registros de Representação. In: MACHADO, S. D. A. et al. Educação Matemática: uma (nova) introdução. São Paulo: Educ, p. 167-175, 2008.

FRANCO, M. L. P. B. Análise de Conteúdo. 2ª ed. Brasília: Liber Livro Editora, 2005.

GIORDAN, M. O Papel da Experimentação no Ensino de Ciências. Química Nova na Escola, v. 10, p. 43-49, 1999.

GUIMARÃES, C. C. Experimentação no ensino de química: caminhos e descaminhos rumo à aprendizagem significativa. Química nova na escola, v. 31, n. 3, p. 198-202, 2009.

GODOY, A. S. Introdução à pesquisa qualitativa e suas possibilidades. Revista de Administração de Empresas, São Paulo, v. 35, n.2, p. 57-63, 1995.

JOHNSTONE, A. H. Teaching of chemistry: Logical or psychological? Chemical Education: Research and Practice in Europe, 1 (1), p. 9 -15, 2000.

JOHNSTONE, A. H. The Future Chape of Chemistry Education. Chemistry Education: Research and Practice, v. 5, n. 3, 2004.

MARCONDES, M.; SOUZA, F.; SUART, R. Atividades experimentais investigativas de química no ensino médio: uma análise das interações verbais e cognitivas. Enseñanza de lãs Ciencias, Número Extra VIII Congreso Internacional sobre Investigación em Didáctica de lãs Ciencias, Barcelona, p. 442-446, 2009.

MINAS GERAIS. Secretaria de Estado da Educação. Projeto de Reformulação Curricular e de Capacitação de Professores do Ensino Médio da Rede Estadual de Minas Gerais. Pressupostos gerais e objetivos da proposta curricular de Química. Belo Horizonte, 1998.

MORTIMER, E. F.; MACHADO, A. H. Química. 3ª ed. São Paulo: Scipione, 2016. v. 3.

NOVAIS, V. L. D. de; ANTUNES, M. T. Vivá Química. $1^{a}$ ed. Curitiba: Positivo, 2016. v. 2.

NÚÑEZ, I. B.; RAMALHO, B. L.; PEREIRA, J. E. As representações semióticas nas provas de química no vestibular da Universidade Federal do Rio Grande do Norte (Brasil): uma aproximação à linguagem científica no ensino das ciências naturais. Revista Iberoamericana De Educación, n. 55 (1), p. 1-13, 2011.

ORNEK, F. Models in Science Education: Applications of Models in Learning and Teaching Science. International Journal of Environmental \& Science Education, v. 3, n. 2, p. 35-45, 2008.

PRAIN, V.; WALDRIP, B. An exploratory study of teachers' and students' use of multi-modal representations os concepts in primary science. International Journal of Science Education, 28(15), 1843-1866, 2006.

REIS, M. Química: Ensino Médio. 2ª Ed. São Paulo: Ática, 2016, v. 2.

REZENDE, B. de P.; SILVA, A. C. A. da. Possibilidades discursivas em atividades experimentais: um estudo dos roteiros investigativos. ACTIO, Curitiba, v. 6, n. 1, p. 1-23, jan./abr. 2021. 
ROCHA, C. J. T. da; MALHEIRO, J. M. da S. Interações dialógicas na experimentação investigativa em um Clube de Ciências: proposição de instrumento de análise metacognitivo. Amaz RECM , v.14 (29) , Especial Metacognição, 2018.

ROZENTALSKI, E. F.; PORTO, P. A. Imagens de orbitais em livros didáticos de química geral no século XX: uma análise semiótica. Investigações em Ensino de Ciências, v. 20(1), p. 181-207, 2015.

SÁ, E. F.; LIMA, M. E. C. C.; AGUIAR JÚNIOR, O. G. de. A Construção de Sentidos para o termo ensino por Investigação no Contexto de um curso de Formação. Investigações em Ensino de Ciências, v. 16, p. 79-102, 2011.

SANTOS, W., MÓL, G. Química Cidadã. 3a ed. São Paulo: AJS, 2016. v. 2.

SASSERON, L. H. Alfabetização científica, ensino por investigação e argumentação: relações entres ciências da natureza e escola. Ensaio Pesquisa em Educação em Ciências, Belo Horizonte, v.17, p. 49-67, 2015.

SCHÖNBORN, K. J.; ANDERSON, T. R. The importance of visual literacy in the education of biochemists. Biochemistry and molecular biology education: a bimonthly publication of the International Union of Biochemistry and Molecular Biology, v. 34, n. 2, p. 94-102, 2006.

SILVA, A. C.; SOUZA, G.; MORAES, J. Os Livros Didáticos de Química: uma Análise das Atividades Investigativas. Revista Insignare Scientia - RIS, v. 2, n. 4, p. 1- 19, 19 dez. 2019. SILVA, A. C. A. da; REZENDE, B. de P. (2021). Análise dos livros didáticos de química: compreendendo os roteiros experimentais de extrato de repolho roxo. Revista Debates em Ensino de Química, v. 6, n. 2, 2020.

SILVA, H. C. da; ZIMMERMANN, E.; CARNEIRO, M. H. da S.; GASTAL, M. L.; CASSIANO, W. S. Cautela ao usar imagens em aulas de ciências. Ciência e Educação, Bauru, v. 12, n. 2, p. 219233, 2006.

SOUZA, K. A. de F. D. de; PORTO, P. A. Estratégias visuais na construção de uma realidade química: análise semiótica das ilustrações em livros didáticos ao longo do século XX. In: VIII Encontro Nacional de Pesquisa em Educação em Ciência. Anais do VIII ENPEC - Encontro Nacional de Pesquisa em Educação em Ciência, 2011.

SUART, R. C. A experimentação no Ensino de Química: Conhecimentos e caminhos. In: SANTANA, E.; SILVA, E. Tópicos em Ensino de Química. Editora Pedro e João Editores, São Carlos, SP, 2014.

SUART, R. D. C.; MARCONDES, M. E. R. A manifestação de habilidades cognitivas em atividades experimentais investigativas no ensino médio de química. Ciências \& Cognição, v. 14, n. 1, p. 50-74, 2009.

TOMIO, D.; GRIMES, C.; RONCHI, D. L.; PIAZZA, F.; REINICKE, K.; PECINI, V. As Imagens no Ensino de Ciências: $O$ que dizem os Estudantes Sobre Elas? Caderno pedagógico. v. 10, n. 1, p. 25-40, 2013.

WEISS, J. P.; LAMBACH, M. Análise epistemológica das propostas de atividades experimentais do capítulo "soluções" dos livros didáticos de química PNLEM 2018. Experiências em Ensino de Ciências, v. 14, n. 1, p. 132-142, 2019. 